\title{
World-wide-welfare: a micro-economic analysis of the new economy
}

Citation for published version (APA):

Herings, P. J. J., \& Schinkel, M. P. (2001). World-wide-welfare: a micro-economic analysis of the new economy. METEOR, Maastricht University School of Business and Economics. METEOR Research Memorandum No. 004 https://doi.org/10.26481/umamet.2001004

Document status and date:

Published: 01/01/2001

DOI:

10.26481/umamet.2001004

Document Version:

Publisher's PDF, also known as Version of record

\section{Please check the document version of this publication:}

- A submitted manuscript is the version of the article upon submission and before peer-review. There can be important differences between the submitted version and the official published version of record.

People interested in the research are advised to contact the author for the final version of the publication, or visit the DOI to the publisher's website.

- The final author version and the galley proof are versions of the publication after peer review.

- The final published version features the final layout of the paper including the volume, issue and page numbers.

Link to publication

\footnotetext{
General rights rights.

- You may freely distribute the URL identifying the publication in the public portal. please follow below link for the End User Agreement:

www.umlib.nl/taverne-license

Take down policy

If you believe that this document breaches copyright please contact us at:

repository@maastrichtuniversity.nl

providing details and we will investigate your claim.
}

Copyright and moral rights for the publications made accessible in the public portal are retained by the authors and/or other copyright owners and it is a condition of accessing publications that users recognise and abide by the legal requirements associated with these

- Users may download and print one copy of any publication from the public portal for the purpose of private study or research.

- You may not further distribute the material or use it for any profit-making activity or commercial gain

If the publication is distributed under the terms of Article $25 \mathrm{fa}$ of the Dutch Copyright Act, indicated by the "Taverne" license above, 


\title{
World-Wide-Welfare: \\ A micro-economic analysis of the new economy
}

\section{P. Jean-Jacques Herings}

\author{
Maarten-Pieter Schinkel
}

\begin{abstract}
In the wide and increasing attention for the so-called 'new economy', two, not necessarily compatible, issues meet the eye. Firstly, most discussions apply macro-economic concepts, yet secondly their general gist is that the new economy demands new tools for analysis. In this paper, the existing micro-economic tool-kit is searched for theories with which a grip on economics associated with digitalized information is possible. To that end we introduce the distinction between commodity-information, information-commodities, and information-infrastructure. It allows for an application of micro-economic insights in various market structures and their welfare consequences to the new economy.

Commodity-information is likely to have a beneficial effect on coordination issues, and thereby the potential to increase welfare. To fully exploit this potential, concerns related to the reliability of information and the confidence in buyers and sellers have to be dealt with. Informationcommodities, however, carry the conditions for the rise of natural monopolies with their negative welfare effects. The same is to an even larger extent true for aspects of the informationinfrastructure. Market developments in both categories are to be kept in check by government through competition policy, if the great world-wide-welfare potential of the new economy is to materialize.
\end{abstract}

JEL-codes: D4, D8, L1, L4.

Keywords: new economy, information, coordination, market structure, infrastructure 


\section{Introduction}

Worldwide, there is an interest in what is generally referred to as 'the new economy'. It concerns the economy, as well as economics, which relates to digital information in the broadest sense of the word, as well as the hardware and software that deals with it. The new thing about that economics is that, as a result of the digitalization of information, its exchange and multiplication can take place at close to zero costs. With that comes that an importantly growing number of people has an ever better wall or mobile connection to the new infrastructure that is formed by the world-wide-web. This allows for a very fast, inexpensive and extensive transportation of information. Information that is increasingly demanded and supplied.

The economic relevance of these developments is large and for now growing. An already large and ever expanding economy flourishes on the internet, in which on virtual markets supply and demand meet. The American research bureau International Data Corporation, for example, predicts that the worldwide trade via the internet will amount to some 1600 billion Euro in three years time, which compares with the gross national product of a country such as Germany. Facilities as e-mail will also soon no longer be available to a small group of 'haves' only. According to the American company Messaging Online, the number of e-mail addresses will surpass the one billion within two years from now.

As a result of the growth of the internet, old physical markets have already been substituted, or are threatened to be replaced soon. On the other hand, many new markets have emerged, such as the one for computer hardware, and many new markets will certainly open. With that, the internet is increasingly responsible for added value, which shows for example in the high value that so-called 'dot-com' firms are given on the Stock Exchanges around the world.

Two of the many things that are written about the subject meet the eye in particular. First, the approach taken is generally a macro-economic one. That is, the effects on macro-economic magnitudes such as national product, price level or employment are discussed. These discussions are often very optimistic. National products and employment will rise for long periods of time, and without any inflation to speak of. Skepsis, although heard, often concerns semantic issues - is the new economy new or not new - or earlier euphorical eulogies of a macro-economic nature.

Secondly, it is regularly concluded that the practice of the new economy demands a reconsideration of economic theory. Old economic laws no longer apply, for new ones have replaced them. Companies, it is for example argued, no longer are required to make profits, but should strive instead at large market shares. It seems also quite generally accepted that it can be sensible to give away products for free when necessary. Because traditional economic relations and laws no longer apply, it seems justified to speak of 'new economics'.

In some sense these two visions are at odds. If one is of the opinion that old theory cannot comprehend new economics, then one cannot support optimism about the effects of the new economy on welfare on the basis of old theories and measurements. And the other way around does optimism on the basis of macro-economic statistics reveal a faith in the applicability of the 
underlying theory. It is therefore of importance to find a theoretical structure applicable to the developments in the new economy, and from there to consider its blessings and plagues.

It is certainly the case that particular traditional insights, such as the existence of a trade-off between unemployment and inflation as represented in the Phillips-curve, or measurement methods based on prices, such as inflation-indices, are less solid and reliable in an economy in which information increasingly flows against decreasing costs. The latter corresponds to the paradox on the national product in heaven and in hell. In heaven, there is no scarcity. All commodities are available in abundance. Consequently, all prices, and hence the national product, are equal to zero. In hell, on the contrary, there is a need for energy to keep the temperature sufficiently high. On top of that, everything is scarce. As a result, all prices and the national product are high. For a determination of the welfare difference in heaven and hell, traditional macro-economic methods of measurement do not apply.

The question we are concerned with here is more modest: isn't it possible to use the concepts developed in economic theory to answer the problem how to efficiently allocate scarce means over alternative ends to shed light on the new economy as well? The discipline in which the allocation issue led to the development of sophisticated models is micro-economics. On the basis of the structure of economies, and the behavior of consumers and producers in it, micro-economics derives conclusions about social welfare. The latter is a consistently defined concept that is not open to the measurement problems such as associated with the national product. Micro-economic theory seems, therefore, specifically suited to make statements about the likely effects of the new economy. It can serve to give hands and feet to either the widespread optimism, or a skeptical attitude.

Since her earliest development, the role of information in understanding societies has been central in micro-economics. The notion of 'invisible hand' associated with Adam Smith, concerns in essence the spread of sufficient information via market prices to make individually optimal decisions socially optimal as well. A common insight is that competitive markets lead to prices in which all available information has had full ramifications. The role of the government in this is a point of heated debate. It goes without saying, however, that the analysis of the production and spread of information is possible with traditional micro-economic insights.

Eventually, the applicability of micro-economic theory falls or stands with the presence of scarcity in the new economy. After all, it is the use of scarce means for alternative ends on which the theory concludes, it is scarcity that determines the prices of commodities, and it is the prices of commodities that guide the invisible hand. Digitalized information after all, can be reproduced and transported without loss of quality and at close to zero costs be multiplied and transported. An unbridled production of information, however, leads to a new type of scarcity, that is, the time it takes to select and consume the right information.

Besides, the concept of 'right information' is rather personal. And it is the technological developments in the new economy that make it possible to offer personalized information. Personal aspects of information make an unlimited production and transportation senseless. A more artificial way to make information scarce consists of obtaining intellectual property rights. The question that rises then is to what extent such rights protect producers of information against illegal reproduction 
of it in the new economy. A last potential source of scarcity is that in the carriers of information, the information-infrastructure.

In this essay, we are concerned with the consequences that large-scale traffic of digitalized information can have for the structure of supply and demand, as well as of competitive processes and therefore social welfare. To that end, the following section contains a micro-economic treatment of information and markets that offers a handle for an analysis of the new economy. We introduce the distinction in information between commodity-information and informationcommodities. Section 3 analyses the consequences of increased commodity-information in the new economy. This concerns commodity-information on traditional commodities as well as information-commodities. Section 4 discusses the specific economic aspects of informationcommodities. Section 5 considers the carriers of information streams, the informationinfrastructure, and particularly several important consequences of the private production thereof. Section 6 concludes with concern for new and specific restrictive tendencies in the new economy.

\section{Information and Commodities}

The central aspect of the new economy is the possibility to reproduce and distribute information at extraordinary low costs, with no loss of quality to speak of. The latter is possible because of the form information takes and the rise of new telecommunications networks, with the internet as a prominent example. We use the term information in the broadest sense of the word. Information is everything that can be digitalized, that is, all that can be put in a series of zeros and ones. The digitalization of information facilitates electronic transportation. Although digitalization is not always feasible - a digitalized signal is only a discrete approximation of an analogous signal - the cut peaks do only really bother the hardened record enthusiast. Examples of information are plentiful. We mention sports results in newspapers, magazine articles, computer programs, medical files, and train schedules. And apart from novels and movies, music is information.

\subsection{A Classification of Information}

In order to unravel the influence of information on decisions, it is useful to make a categorization. The first and most elementary distinction is that between pure and instrumental information. ${ }^{1}$ Pure information is information that is a direct source of utility, or information that is directly used as an input factor in a production process. It is a consumption good or a production factor, that is theoretically distinct from the carrier. An example of information as a consumption good is a movie, but then without the cinema. An example of information as a production factor is a word processor, but without the CD-rom. Pure information is a commodity and is therefore characterized just like other commodities, by content, time and place of availability, and state-of-the-world at the time of availability. ${ }^{2}$ We refer to pure information as 'information-commodity'. Informationcommodities appear as arguments in the utility function of consumers and in the production function of producers.

Instrumental information, on the contrary, is information about things that provide direct utility or that serve as production factors. It is commodity-information, such as the information that a certain movie plays at a certain time in a certain theater, or information about the availability of certain type of production factors. Commodity-information is in the micro-economic literature generally 
represented by a probability distribution over the set of possible states-of-the-world. In case of complete commodity-information, there is no uncertainty and the distribution over possible statesof-the-world is degenerated. In case of incomplete commodity-information, economic agents base their decisions on a non-degenerated distribution. New commodity-information generally leads to an update of this distribution. Commodity-information, therefore, is closely related to the theory of choice under uncertainty. ${ }^{3}$ Commodity-information can be put in the preferences of consumers and the production technologies of producers, since commodity-information leads to a distribution over physical characteristics of commodities or the characteristics and possibilities of certain production processes.

Where information-commodities appear directly in the utility function, commodity-information specifies the choice problem of economic agents, in which preferences play a part next to possibilities. Commodity-information has little value in itself. It only derives worth from the possibility to make better choices. It serves, for example, to better enjoy the informationcommodity movie by being in time for the show, or to make lemonade more efficiently out of lemons - which in essence is the same. Also, information that producers obtain about the buying behavior and preferences of their customers - and for this the internet offers plenty of opportunities - heads in this categorization under commodity-information. Commodity-information is information about the elements of the commodity vector, including information-commodities. Information is very often available in both forms simultaneously. A film review, for example, is both an information-commodity - as it often is amusing reading - and commodity-information, since it leads to better choices in the matter of theater visits. An element of commodity-information that attracts a lot of attention in the economic literature is the price of a commodity - whether information-commodity or otherwise.

It is important in this context to note the difference between the interpretation of one and the same piece of commodity-information by different people. On the basis of the same signals from the outside world, different economic agents are likely to form different expectations. This has to do with both the structure of the view of the world that someone has, and with the initial probabilities that are assigned to possible developments within that structure, and on which extra information exerts an influence. In Section 3 on commodity-information we come back to this. In general, when different individuals are confronted with very much identical information, they tend to form very similar expectations. ${ }^{4}$

The indirect value of information may cause commodity-information to be traded as if it were a commodity. The information what movie plays when, could be offered for sale - generally it is of course offered for free. Another, and perhaps better, example of tradable commodity-information is the information necessary for the sellers and potential buyers of houses to find each other. The trade in this commodity, that consists of commodity-information, earns real-estate brokers their daily bread. Their well-being, however, depends on the latter only.

Although information can therefore be analyzed separate from the carrier, it cannot exist separately from it. ${ }^{5}$ To be useful, it has to be stored, for example on compact disks, on paper, or in memories. The more traditional carriers and the technology compatible with them add characteristics to the combination of information and carrier, that make the total product a standard commodity in the economic sense. An example is again the information-commodity movie that is to be watched on 
celluloid in a movie theater. As a result, a price can be charged for it. That is also necessary, given the fact that the amount of seats in the cinema is limited. Also the information printed in the consumers' magazine is tied to a paper carrier that needs to be acquired. Tradable commodityinformation obtains the characteristics of a traditional commodity, and is characterized by content, time and place of availability, as well as state-of-the-world. Contrary to information-commodities, there is no direct use in consumption or production. Instead it serves to support consumption and production decisions.

The development around the information-infrastructure such as the internet, the wireless phone and the necessary equipment are interesting because it makes the tie between information and carrier less rigid. As a result of decreasing scarcity in carriers such as digital memory, the special characteristics of information as a commodity, information-commodity and tradable commodityinformation, play a larger role. As a result of the cheaper transportation of information, the place of availability is of ever lesser concern. For producers, this implies that a traditionally important element on which to build monopoly power disappears. Apart form that, the technological progress leads to new applications of information, applications that before were simply not feasible or too expensive.

\subsection{Specific Characteristics of Information}

Both the production and the distribution of information are different from those of physical commodities in important ways. Its special characteristics here were recognized in an early stage already by Kenneth Arrow (1962). He observed that the production of new information generally requires high fixed costs, that are largely sunk once made. Writing a book, for example, demands a special effort of the writer. Once this production has taken place, however, reproduction is easy and can take place at relatively low costs. This is the case with books since the invention of the art of printing, but more recently it holds for copying computer software as well. The marginal costs necessary for the production of information are nil.

This asymmetry between fixed and marginal costs causes a number of important problems. Because copying is simple, information once produced spreads quickly and easy. As a result, it is questionable whether someone is willing to make the initial investment in the production of new information. After all, there is a real possibility that it will not be possible to earn the investment back. The consequences of this are all the more disastrous when one takes the public good aspect of information into account. Naturally, this is the basis of intellectual property rights, to which we return in Section 4.4.

Information, therefore, can be transmitted from one individual to the next. In that information has the characteristic noted by Arrow that when it passes from one individual to the next, it remains part of the endowment of the offering party. In most cases this is evident for commodityinformation, but for information-commodities is holds equally true, given the ease with which these commodities can be multiplied. Trade in information, therefore, always involves its multiplication - unless such is not desired, but then the carrier of the message should be destroyed, or destroy itself. Information is, as a result, not necessarily a commodity for which there exists rivalry, and it therefore carries a characteristic of public goods. 
Communication of information can also take place unintended. An example is leakage of information. This happens relatively easily, particularly because information can be exchanged without deterioration and at low costs. In a way, information has as a consequence of these characteristics a natural tendency to spread. After all, such may happen against low costs and without loss of information for the original owner. In many cases, the leakage of information is actually very desirable. In general it is socially optimal when information, once produced, is made public to as large a group as possible. The catch is of course in the condition that the information should already exist.

Another special aspect of information is that the determination of its value is hard without consuming it. Information, in other words, is an experience good. This causes problems in its transmission. Decisions on the purchase of information, as a consequence, are generally decisions under uncertainty. We return to the specific possibilities that the new economy offers for trade in information-commodities.

In many cases, the tendency of information to spread also allows for abuse. Economic agents can have an incentive to leak misleading and false information. A traditional example of the spread of such information concerns the announcement of business news in an attempt to manipulate the price of the stocks. For these reasons in the past many a newly discovered gold mine has been announced.

As a result, the reliability of offered or already obtained information is an important part of the economic analysis of information. In order to be able to judge the reliability of information, it is for example often important to know who spread it, how many others already have used it, and who knows who has what information. That way, it can be determined whether the information was brought out with specific perverse incentives. Information can, for this purpose, be categorized in three different orders: first-order information is the actual information - as information-commodity of commodity-information - and higher-order information is information about the information. Again the movie example applies. A review constitutes first-order commodity-information about the information-commodity movie. Second-order commodity-information about the review is the newspaper in which it appeared, or the identity of the reviewer.

A special case of higher-order information is the so-called common knowledge. This is information of which everybody knows that everybody has it. Such information is a strong form of public information, which is information that everybody has, but of which it is not necessarily known that such is the case. It contrasts sharply with private information, which is information that is available only to one individual. The natural tendency of information to spread easily creates a tendency towards private information - for example privately produced information for which costs have been made - to public information and finally common knowledge.

\section{Commodity-information}

Commodity-information has been defined in the previous section as knowledge about commodities and services that allow consumers and producers to specify their choice problems. Commodityinformation comes in many varieties. It concerns, for example, the price of a commodity, the physical characteristics of a good, or the probability with which future developments take place. In 
general, and ignoring for now the costs associated with the storage and selection of information, the choices the agents make are more beneficial for them, the more specific information they have available. After al, having more information makes them come equipped to compare different alternatives, while the original option is still available. ${ }^{6}$ As a result commodity-information has a derived value for individuals.

\subsection{The Individual Value of Commodity-information}

What is the derived value of commodity-information? A somewhat naive approach consists of comparing the choices made without and with commodity-information. A conundrum that arises here is that ex ante it is, of course, not known what the return of that commodity-information will be. Making use of modern information and communication technology often delivers commodityinformation about commodities about which ex ante the existence was not even known. Another problem by simply comparing ex ante and ex post made choices is that a choice after collecting more information can, solely due to coincidence, turn out to be worse than a decision made with less information, even when the information was actually reliable and valuable.

Collecting information by an economic agent results in a message $m=1, \ldots, M$. The joint probability distribution of message $\mathrm{m}$ and state $\mathrm{s}$ depends on the view of the world of the economic agent. The standard micro-economic model with which to value commodity-information is as follows. Assume that an economic agent has a choice between taking immediate action, or first collecting information with the idea to take, a perhaps different, action. Call the possible action $\mathrm{a}=1, \ldots, \mathrm{A}$ and the collection of states of the world $s=1, \ldots, S$. The choice for an action by an individual, together with the selection of a state of the world by chance, results in a pay-off $u_{a s}$. We accept expected utility maximization. Initially, the economic agent expects that state $s$ arises with probability $p_{\text {is, }}$ also called the prior. An economic agent can choose to collect information on the basis of which he changes his prior distribution. Let $\mathrm{p}_{\mathrm{m}}$ be the probability with which message $\mathrm{m}$ is received, $\mathrm{q}_{\mathrm{ms}}$ the joint probability of message $\mathrm{m}$ and state $\mathrm{s}$, and $\mathrm{p}_{\mathrm{m}}$ the conditional probability of message $\mathrm{m}$ given state $\mathrm{s}$. The so-called posterior distribution $\square_{\mathrm{sm}}$, that is, the conditional probability of state $\mathrm{s}$ given message $\mathrm{m}$, is then easily derived using Bayes' law. ${ }^{7}$ On the basis of this mode it is possible to determine whether or not an individual will collect information. The utility value of message $\mathrm{m}$ is equal to the expected utility of the optimal choice made after receiving message $\mathrm{m}$ minus the expected utility of the optimal choice made without the message. In both cases the same, revised, probability distribution is used.

The above model also allows for a further sharpening of the distinction between commodityinformation and information-commodities. Commodity-information complies with the information defined as follows in Arrow (1978): 'By "information", I mean any observation which effectively changes probabilities according to the principles of conditional probability." This is only part of our definition of information as everything that can be represented in a stream of zeros and ones, since the latter is also possible for information-commodities such as music, while listening to music will scarcely give reason to a reconsideration of the probabilities with which future developments are foreseen.

The utility value of a message is always positive. The expected value of information is the expected value under the prior of the utility values when all possible messages are taken together. It 
determines how much somebody would maximally want to pay for the use of a certain message service, such as a newspaper, and internet site or an expert. In this way it is possible to compare the value of information services, and rank them. As the subjective world views determine the value of an information service, economic agents rank information services differently. On top of that, the above analysis does not take into account that there are costs associated with the processing and use of information. These capacities differ for different agents as well. We therefore expect that several information services will come to co-exist on the internet.

It is to be expected that information is different for people with a different attitude towards risk. Intuitively a risk-averse person would want to make more costs for collecting information before taking a decision than someone with less aversion towards risk. This is not necessarily so, however. If the optimal action without first obtaining information leads with certainty to a particular pay-off, a more risk-averse individual will actually optimally collect less information. The possible variations in income resulting from the new information are not particularly appreciated. The other way around, if collecting information reveals the state of the world with certainty, a risk averse person collects more information. Extra information, however, always has a non-negative value, for risk-loving as well as risk-averse people.

A better match between the real probabilities with which events can take place and the subjective expectation of it, therefore, is desirable for the individual decision maker. There is no gain in seeing bears on the road that are not there. The importantly improved means to communicate offered at low costs in the new economy therefore certainly have a private value. A larger transparency of possibilities and restrains, as a consequence, has a positive effect on social welfare when the choices of individuals are seen in the context of an economy. It has a transaction costs decreasing effect and a competition enhancing effect.

\subsection{The Social Value of Commodity-information}

General equilibrium models are models in which the social consequences of individual choices in certain economic market structures find expression. They are to be understood as limit models. Although not inherently, the most important results in general equilibrium models are found in worlds with rational agents, markets with perfect competition and the absence of transaction costs.

In short, the findings of the general equilibrium research amount to the following. Consider an economy with a complete system of markets, which means that at each point in time there exist markets for commodities that are available at that point in time, but also for all commodities that come available in the future, possibly conditional on the realization of future uncertain events. The information about future commodities that is present initially, is in general asymmetrically distributed over the economic agents. The equilibrium prices that result in such an economy, however, are such that all existing information is revealed. ${ }^{8}$

It is possible to relax the assumption of the existence of a complete system of markets to the (still strong) condition that a complete system of financial markets exists, or alternatively put, that agents are able to insure themselves against all possible events. This complies with the more general idea that a system with complete financial markets leads to the same result as a system with complete commodity markets. ${ }^{9}$ It should be noted however that, although equilibria in both market systems 
have identical characteristics, the conditions under which coordination on an equilibrium takes place differ. ${ }^{10}$

Outside of the context of general equilibrium, auction theory concerns the question whether perfect competition leads to a complete revelation of all available information. Consider the situation in which an object is auctioned that represents the same value for all, a value that is unknown. Every participant knows this value, however, and the information of all participants together is sufficient to determine the value of the object. For both a decreasing auction and an increasing auction in which the highest bidder pays the second highest price, the winning bid is equal to the actual value of the object if the number of participants is sufficiently large. ${ }^{11}$

These results are very powerful. They show that in an economy with sufficient competition, information problems play no role. Economic agents can use market equilibrium prices to obtain all available commodity-information. The level of rationality necessary for this, however, is staggering, and by far surpasses the level demanded in a standard general equilibrium model, as it assumes structural knowledge, such as insight into the preferences of individuals. The important lesson learned from these models is that commodity-prices reveal a large portion of commodityinformation. The added value of the new economy for as far as it concerns the increased commodity-information, therefore, are likely to be lower than one may initially think. It is, however, certainly not negligible. Models that conclude that all commodity-information can be distilled from the market prices assume the absence of transaction costs as well as an instantaneous spread of information over all prices. It is particularly these assumptions that gain in empirical relevance thanks to the new economy. An important conclusion then is that, as a result of the new economy, commodity-information will be better absorbed in market prices.

\subsection{A Disequilibrium Approach}

In the absence of a complete system of commodity markets, the usual equilibrium concept in general equilibrium theory takes out a loan on rationality. Economic subjects not only need to know the prices of commodities, they are also required to have insight into 'the model' of the economy. Originally, this is the idea behind the long popular but increasingly questioned 'rational expectations approach'. The idea is that if economists know the model, economic agents should be assumed to be able to know it as well. Therefore, they should not be off the mark in their predictions of equilibrium values. There is, however, an important difference between structural insights into economies and parametric knowledge of it. For both, but especially the latter, an unreasonable amount of information is demanded.

Interestingly enough, the literature on rational expectations as justification of the equilibrium approach has pushed aside the ideas of economists such as Friedrich von Hayek and Kenneth Arrow, that apply much better to the new economy. They argued that competitive economies are not to be praised particularly for the existence of Pareto efficient equilibria, but for the fact that the competitive process is an important distributor of information. Rival bids and bargaining will reveal options to others they were previously unaware of, so that prices paid will eventually gravitate towards values that reflect the marginal costs of goods. The competitive process thus leads to efficiency, but along an adjustment process in which information plays a crucial role. 
It is particularly in this disequilibrium sense that an important influence is to be expected from developments such as the growth of modern information and communication technology. As these technologies accommodate a fast distribution of information, they enhance competition. Consumers are better able to compare price and quality of different suppliers. As a result suppliers will have to offer better price-quality ratio's and will find their margins under pressure. On top of that, on a number of markets the role of intermediaries is played out.

Illustrative examples of the latter are brokers in houses, or dealers in second-hand cars. Although these intermediaries do have their own added value in determining the quality of the goods offered, that function apparently does not justify the fees paid for their services in the past. Particularly as a result of the increase in communication that runs via the internet, these margins have recently decreased importantly. Indeed, for a large part they used to be derived from the difficulties that buyers and sellers in the market have in finding each other. These search costs are the direct consequence of intransparencies of markets and forms of inefficient transaction costs. In the new economy a decrease of such costs is to be expected and an increase of competitive pressures on both suppliers and demanders. The result is that reality will increasingly become like the competitive general equilibrium models with their noise efficiency properties. Such is highly socially desirable.

With a flourishing new economy there seem to be both private and social benefits to be reaped. A better connection between desires and possibilities on an economy-wide scale can lead to an important increase in social welfare. Nevertheless, it is of importance to make some qualifications with respect to too unbridled enthusiasm based on this type of argument. It follows, for example, that no unlimited growth needs to be expected if the benefits of the new economy are particularly found in the resolution of inefficiencies in the old one. Growth is then more likely to take the form of a temporary spurt, after which an equilibrium is reached on a permanently higher level of welfare.

Apart from this, there are a few more structural aspects one needs to take into consideration before being overly optimistic. They concern the costs of information and the related potential development of market structures in the new economy.

\subsection{Information Costs}

So far, the analysis departed from the assumption that either all relevant commodity-information was available for everybody, so that results are to be seen as the ideal case scenario for the new economy, or that it can be obtained at close to zero cost, in which the new information and communication technology plays an important part. Collecting, storing and processing information, however, will generally involve costs. If commodity-information can only be obtained and used at a cost, it is still true in general that more information leads to more efficient choices. The efficient amount of information to collect, however, is no longer equal to the total of relevant information. If the marginal contribution to the decision problem is equal to the marginal costs of getting the information, one should stop further inquiries and take a decision.

In many decision problems there is not one single economic agent that decides, but a group that takes decisions collectively. If the members of the group have different expectations or different 
objectives, there is a tendency to collect too much information. In the case of different expectations, the reason for this lies in the fact that the individual expectations about the pay-offs of actions that are far in the future only coincide when large amounts of identical information are shared by the members of the group. Inefficiently large amounts of information then only serve to justify an otherwise unavoidable decision for all. If there are different objectives, collecting more information helps to put off decisions and keeping alternatives open. In both cases abundant information may well have a negative influence on welfare. ${ }^{12}$

There is yet another important social danger that lures when too much information is available. The argument that individuals are better off with more information because they then have a better ability to determine the consequences of their choices, is based on the assumption that no options of choice disappear when more information comes available. This is certainly not always the case. Some markets exist only by the grace of incomplete information. A well-known example of this is the insurance market. If it is possible to determine with certainty that someone suffers from a certain illness or will be struck by disaster, there is no possibility of insuring against it. In other words, after revelation of the state of the world it is no longer possible to insure oneself. Such can lead to important welfare losses. ${ }^{13}$

The above mentioned negative consequences of information, the collection of which comes with costs, increase the costs of obtaining information. This latter effect, that goes directly against the transaction costs decreasing effect of new information and communication technologies, is a certain danger that exists in the new economy. As a result of the large supply of information on the internet, it has become increasingly difficult to separate important from less important, useless, or even false, information. This introduces at least two new problems. In the first place does the overload of information require storage capacity and time to come to a selection of valuable and less valuable information. In the second place, and this problem is aggravated by the latter, the reliability of information is not always easily determined and extra costs are to be made in their verification.

\subsection{Virtual Markets}

The necessity to select and verify information generates direct costs, but it also has consequences for market structures, especially the structure of virtual markets. Has it already been noted that the increase in available information reduces the role of certain traditional intermediaries, it also creates room for new ones, namely intermediaries that select and provide custom made information. Search engines already play this part to some extent. The high prices paid for sites such as Startpagina.nl are indicative in this respect. This type of organizing search engines will most certainly be developed further to better play into the specific interests on the demanders of commodity-information. The question remains, however, whether they will ever be able to compete with human consultants, even where it concerns relatively easy tasks, such as those of travel agents that propose suitable trips on the basis of just a few parameters. When a search engine that has this potential has been developed, it will exercise a local monopoly power over anyone that uses it. In other words, the overflow of information creates a scarcity of time to select the rights things, which in turn creates market power. 
The reputation of suppliers on virtual markets are of a great concern for the establishment of transactions. Where it concerns commodity-information, the internet creates intervals between the different elements of an economic transaction. When someone buys a book in a local store, he or she pays while the book is being wrapped up and it can be taken out immediately. A transaction with Amazon.com, however, involves an impersonal electronic order, that requires something like a credit card number, after which it takes some time, sometimes up to several weeks, before the item, which then has already been paid for, is delivered by mail. Because there is no cash on the nail, both the method of payment and the lapse of time ask for trust of the buyer in the system of the seller, as well as trust of the seller in the credibility of the buyer.

This has several negative effects. Starting entrepreneurs will have to build confidence among consumers, and such can be very difficult when there are already well-established large incumbents. This is apart from the fact that the incumbent is likely to have scale economies already, for example in the access to distribution channels. As a result of these problems, market power rises, that can nullify large parts of the efficiency enlarging possibilities of the increased means for communication. Reputation becomes an important barrier to entry as a result.

Players that will become crucial in the internet transactions are credit card companies. They accommodate the larger part of the internet transactions by means of virtual payments. In order to prevent hesitation and reluctance to trade on the internet, credit card companies offer, although not always with wide notification, a guarantee against potential fraudulent use of credit card numbers. They have an obligation to do so even, after all, payments via the internet usually take place without proper identification of the buyers, and the obligation of such identification lies with the selling firm. As a result, it is likely already that virtual transactions are more expensive in comparison with the physical ones, due to the intervention of credit card companies. Given the increased risks related to the impersonal transactions, these margins will rise rather than fall, because they will have to cover either a margin of risk, or the costs of a more careful identification.

Another problem is that credit cards are not suitable for all types of transactions on the internet. ${ }^{14}$ The internet is particularly suitable for one-to-one transactions between individuals, but credit card payments are not. Cash payment methods, or bank wires, do on the contrary not fit when transactions are to be completed immediately. For other uses on the internet, it is important to make payments in very small units. An example is downloading information for the price of just a fraction of a cent. Here again, credit cards are not the most suitable because they require a minimum sum to cover the transaction costs. Although alternative methods of payment have been developed on the internet, confidence problems play an even greater role there.

Confidence issues in payments clearly have the potential to reduce the potential efficiency gains in the new economy. A lack of confidence will put a certain upper bound to transactions on the internet. In this context, extensive research has been done into drugs transactions. In the drugs trade, there have always existed confidence issues, simply because there is no possibility for falling back on a judicial system for sanctions. Larger transactions are, as a result, split in smaller parts. It has been observed even that dealer and customer exchange little suitcases with drugs and money in several transactions following each other, in order to reduce the risks of unilateral default. It is not unthinkable that comparable risks of unilateral failure to close a deal in internet transactions will 
put a similar type of upper limit to these transactions. Larger ones will then only take place in a personal meeting, even though parties may find each other via telecommunication. ${ }^{15}$

New intermediaries specialize in providing the identification to reduce confidence problems. Even though they cannot give watertight identification, they reduce the risk of larger transactions considerably, be it at a cost. Moreover, the increased role as an insurance company of credit card companies leads to a drive for size. After all, the more transactions, the lower the variance in returns due to mal-payment and fraudulent use. Together with the reputation effects that hold for credit card companies as well, this effect kills competition in the payment traffic. ${ }^{16}$

A confidence problem on the side of the buyer is the fact that it is intransparent which consequences placing an order on the internet has for his or her anonymity. In traditional transactions, apart maybe from the local supermarket, some anonymity is guaranteed. The payment can take place with non-traceable money and the parties split up. Internet transactions, already the actual surfing to obtain information, reveal the preferences and purchases of the customer and offer the possibility to store, and therefore use and exploit that information for many years to come. Several methods to protect private information are being developed. ${ }^{17}$ For example, some companies announce not to use personal information. Also, there exist internet banks where money can be put and from where anonymous payments can be made. It is particularly the intransparency concerning the possibilities and impossibilities of undesired use of private information that can be an important cause of reluctance to trade on virtual markets.

Almost all thinkable products have aspects of experience goods. Sometimes it is possible to determine the quality of a good by means of an intermediary. In many cases, however, the buyer would not want to delegate the quality inspection process. In case of relatively large purchases, such as a house or a classic car, but also in many smaller ones, such as buying the ingredients of an important dinner, the final decision to buy will be made only after a personal inspection of the goods. This means that physical markets will remain necessary. Although the information that is spread via the virtual markets provides a much better insight into the total market and therefore the relevant prices, which will put pressure on the prices in the physical markets a well, the latter will no doubt maintain an important function.

A different type of restriction for trade on the internet is the fact that it often concerns physical commodities, for which transport from the seller to the buyer is required. In a geographically organized market, this is largely the problem of the buyer. For the seller it suffices to stock his store. Virtual markets for traditional commodities, however, require a delivery network that is comparable to a post-order delivery system. This involves new problems in planning and use, for example the road network for door to door delivery. After all, the number of movements is importantly larger than is the case in traditional markets. Scarcity in the sectors can well lead to congestion that reduces the benefits of electronic trade. These problems are increased by the fact that one of the ways to solve the confidence problems discussed earlier is to offer good service, including the option to return goods that are not of one's liking. Although such service will stimulate orders via the internet, it also enlarges the congestion problems that restrict virtual trade.

Even if the commodity-information offered is reliable, it can be incomplete. It is not easy to compare prices on the internet, with or without an intermediary. A transparent site is the already 
mentioned Amazon.com. Even there, however, it demands quite some work to establish the exact price of an item, including the transportation costs. As there does not exist a simple standard by which one can easily compare prices, there remains scope for monopolistic competition and costly intermediaries.

Stronger than this even, suppose that the virtual markets would be in perfect competition, then none of the consumers has an incentive to make expenses in order to search for commodity-information, not even when these are very small, such as is the case with the internet. Likewise, web-sites with comparing price information for homogeneous commodities can only exist by the grace of price dispersion. This type of sites therefore has an incentive to leave a certain amount of price dispersion remaining, since that provides the rights to their existence and their profit opportunity. ${ }^{18}$

Web-sites of other intermediaries with comparable price information can be incomplete in the sense that they do not include all sellers of a product. For several reasons, suppliers of a product can reject to provide price information. This can be because the supplier is too expensive. An inefficient supplier that is simply too expensive has little incentive to advertise with its price on a web-site with comparable prices. A supplier can, however, also refuse to reveal its price, because its products are of higher quality than the products of its competitors. Such a seller would want to avoid one-dimensional competition on price. It is even not unthinkable that a seller with a lower price will not reveal this price to an anonymous web-page. This is the case when the low price generates a loss on the product, but serves to tempt consumers to inquire with the other products of the seller, and have them buy other products, on which profits are made. ${ }^{19}$

A different factor that hinders the rise of markets with perfect competition, is that the internet accommodates both sellers and buyers in their organization. Where a market with perfect competition is based in many small consumers and producers without any personal influence, does the organization of buyers and sellers lead to market structures with large sales and purchase organizations with a lot of power. The market structure with anonymous sellers and buyers then changes into a structure with readily identifiable parties that come to transactions by bargaining. ${ }^{20}$

In a market with sufficiently many competing sellers, an efficient and reliable information service gives rise to strong pressure from potential competition. This induces a collective incentive among the sellers to make the internet into the type of unreliable and uninformative medium that television is with commercials. In that case, the informative role has been pushed away by entertaining and manipulative functions, that strengthen the positions of market power. This is a clear and present danger.

\section{Information-commodities}

In this section we address the second important product of the new economy: pure information in the form of information-commodities. By information-commodities we mean all commodities which can be represented digitally and which are directly used in consumption processes to acquire utility or in production processes to obtain more output. Consumers value information-commodities because of their entertainment value. Typical examples of information-commodities are books, compact disks, databases which contain interesting information, and, of course, web-pages. The easy distribution of information-commodities by means of the modern communication and 
information technology has already caused a substantial increase in the well-being of many, and will increasingly continue to do so.

For an economic understanding of information-commodities, it is important to notice the characteristic cost structure of the production and distribution of information. Fixed and sunk costs are high. Marginal costs of reproduction and distribution are nil. Sunk costs are particularly important for information-commodities. As for any other commodity, it is possible that an information-commodity doesn't fly. Since its alternative uses are typically limited, the already incurred costs of production can then not be recouped. The marginal production costs of information-commodities are low. As soon as the first copy of an information-commodity has been produced, its digital character allows for a multiplication and distribution at virtually no costs, for instance by means of the internet. On top of this, there are hardly any capacity constraints.

Another important property of information-commodities is that they are pre-eminent examples of experience goods. This is obviously the case for commodities with a high entertainment value such as movies and novels, but also for those information-commodities that serve as a message service like a newspaper, and certainly for information-commodities like software. A consumer is only able to judge such goods on their merits after he or she has had some time to try them.

The high fixed costs of information-commodities make it far from socially optimal to produce all imaginable information-commodities, even though the costs of reproduction and distribution are zero. The social benefits of an information-commodity need to exceed its fixed costs to make its production desirable. As soon as an information-commodity has been produced, and is therefore available, social optimality requires that each and every person that associates a positive value with the information-commodity, or would potentially do so after experiencing the commodity, has it available. The socially optimal distribution of information-commodities is completely symmetric.

Reality differs substantially from this social optimum. Money is made on information-commodities by charging non-negligible prices for them and by restricting their distribution. This is not only so for Microsoft's Windows, but also for publishers of books and music, or for old movies, which are only available at prices that are excessive when compared to the costs of reproduction and distribution.

The cost structure of information-commodities, and the fact that they are experience goods, has a number of consequences, which are studied in depth in this section.

\subsection{Market Structure}

The underlying structure of demand and supply for information-commodities makes the market structure of perfect competition with its many small suppliers who behave as price takers very unlikely. The ultimately evolving market structure will display high concentration rates instead. In most cases either a natural monopoly will result, or a market structure with one dominant firm and a number of small competitors, or a market structure of monopolistic competition, where a number of firms offers variations of basically the same product. 
Even though there are few industries where increasing returns to scale take the extreme form of the production of information-commodities, strongly increasing returns to scale are not a new phenomenon in economics. The production of airplanes is a very well-known example. Comparably strong increasing returns to scale are also present in the airline industry as long as an airplane is not filled. However, in these traditional industries capacity constraints are much more clearly present, which implies that increasing returns to scale are not unlimited there. This makes traditional industries somewhat different from industries producing information-commodities.

Although the long-run market structure of information-commodities has monopolistic features, the way towards it is often characterized by severe competition between producers of the same information-commodity. Suppose that there are two firms which offer a similar informationcommodity, whereas both have already incurred their first copy cost. Both firms will be in pursuit of an as large as possible market share to keep variable costs of production as low as possible. Bertrand competition will ultimately lead to sales at marginal costs: a zero price, in accordance with the conditions for a Pareto efficient allocation, which require that the price of a commodity with zero marginal production costs is nil.

The importance of exploiting increasing returns to scale, creates a first-mover advantage when selling an information-commodity in large amounts. There are strong incentives to be the first to produce an information-commodity and to quickly build up a huge market share. The incentive to be the first causes large investments in research and development, perhaps too large. ${ }^{21}$ The incentives to build up market shares makes high outlays on advertisement unavoidable. Producing at a larger scale than all competitors creates a cost advantage. This cost advantage enables a firm to further increase the competitive edge with its competitors and to maintain its market share.

Another reason for high outlays on advertisement is the fact that experience goods are pre-eminent examples of experience goods. An information-commodity such as a message service or a television series, with repeated sales and consumption, enables a producer to acquire a reputation for being a high quality supplier. For an information-commodity that is sold only once, it is more difficult to build up a reputation by means of selling high quality. Problems of adverse selection are likely to occur if it is difficult for a consumer to distinguish high-quality from inferior informationcommodities. ${ }^{22}$ Consumers who are not able to assess the value of an information-commodity, will infer that the information-commodities offered for sale are low-quality, and will decide not to buy. This may prevent mutually advantageous trade from taking place.

Sellers may use advertisement to escape problems caused by asymmetric information. Suppliers of high-quality information-commodities in particular may signal high quality by means of a well thought-out advertisement policy. Suppliers of information-commodities with a beneficial price quality ratio, have higher profits per unit sold than suppliers that are less efficient. This increases their incentives to spend money on advertisements. In addition to this, advertisement outlays may serve to build up a brand name that sustains a strong reputation. This provides producers of information-commodities with additional reasons to make high expenses on advertisement. ${ }^{23}$ The issues mentioned in this paragraph thus further strengthen the tendencies towards monopoly.

We have argued that the road to monopoly is paved with intense price wars as soon as the structure of competition evolves into the Bertrand-type with homogeneous products. As a consequence, 
producers of information-commodities have strong incentives to avoid Bertrand competition, as well as to protect monopoly positions that they have built up. The common instruments to achieve these goals are product differentiation, the lock-in of existing customers and the protection of information-commodities by means of intellectual property rights.

\subsection{Product Differentiation}

Whenever possible, producers of information-commodities will try to differentiate their product from the ones of their competitors. In this way, they try to maintain and enforce their monopoly positions. It is, however, more difficult to differentiate one's product than it may appear to be at first sight. Many forms of product differentiation do not stand the test of imitation. This is even more so as the internet makes imitation quite simple in many cases.

The new economy also offers possibilities for product differentiation that were traditionally less readily available. The internet offers much information about customers, which makes it possible to offer a tailor-made information-commodity. Information acquisition on customers is possible by studying the past sales records of consumers, the terms they used in search engines, as well as the search behavior in web-pages. Suppliers of information-commodities often request demographic information when clients register for their products. It is, for example, customary to ask for information on ZIP codes, age and gender. This information can also be obtained in the billing process. Such information is of crucial importance for formulating advertising strategies, since it allows for well-focused campaigns. The other side of the coin is that consumers will realize that such information can be used against them. This makes them unwilling to provide personal characteristics. Also in this case, the reputation of a supplier might be the decisive factor to provide such information. The importance of reputation is detrimental to the formation and development of a competitive market.

Another specific characteristic of the new economy, the abundance of information, offers opportunities when it concerns the realization of product differentiation. A form of product differentiation which is not apt for immediate imitation is to increase the value of informationcommodities by means of an appropriate selection of information. The web sites that are most popular today, offer exactly these kinds of information-commodities.

\subsection{Lock-in}

Suppliers of information-commodities are certain to use the opportunity of keeping once acquired customers by incorporating a sufficient amount of switching costs. In this respect it is helpful to such suppliers that for many information-commodities lock-in arises in a natural way. Moreover, the amount of lock-in is a parameter that can be influenced by the supplier of an informationcommodities. This will play a prominent role in the strategic plan of many a supplier.

Consider the situation where a number of suppliers each offer a similar information-commodity for sale. At the moment that a supplier has chosen a certain information-commodity, it will often be difficult to make use of another supplier because of switching costs. For an information-commodity like a word processor, the switching costs do not only involve the investment of the time needed to learn working with a new program. The choice for a new software package often implies the 
necessity to rework old files, a lack of compatibility with other software, an increased difficulty to communicate with others, and so on.

More generally, consumers invest in a relationship with the supplier of an information-commodity. These investments are typically relationship specific, which implies that a consumer who changes to another supplier has to make all these investments once again. This kind of investments does not only involve physical investments as is the case for instance in the software example mentioned above, but also investments in time to reveal personal preferences to a supplier. In particular the possibility to fine-tune information-commodities to a specific consumer, lead to high relationspecific investments, and thereby to lock-in.

After a consumer has chosen a particular information-commodity, the producer of that informationcommodity obtains a monopoly position with respect to that consumer when switching costs are high. A consumer who realizes that he or she becomes a sitting duck after lock-in, may decide not to buy. As a fortunate circumstance, this restricts the possibilities of lock-in somewhat. It is also the case that a consumer who will become locked-in is in the position to negotiate ex ante for attractive discounts. When a sufficient amount of competition is present and consumers are rational, a producer will only achieve a normal rate of return, even in the presence of lock-in, and a form of monopoly power ex post. The discount a producer gives initially as a teaser, will have to outweigh the consumer surplus appropriated by a producer later as a consequence of consumer lock-in.

Lock-in reinforces the concern of producers to strive fast for a large market share. At the moment that a consumer has made a choice for a certain product, and thereby falls prey to lock-in, it will be difficult to switch to a competitor. Waiting too long to land customers has as a consequence that many customers are lost forever.

A supplier of information-commodities will try hard to further increase switching costs, for instance by selling complementary information-commodities, by affecting long-lasting contracts, and by giving quantity discounts. In particular the combination of a monopolist and lock-in may cause great harm. In this case, consumers do no longer have the possibility of an effective negotiation before closing the deal, whereas the potentially disciplining force of new entrants is absent.

\subsection{Intellectual Property Rights}

Another means producers have available to monopolize information-commodities, is to build up intellectual property rights. The standard argument given by economics for assigning property rights, is that these rights enable producers to retrieve sunk costs by means of a temporary monopoly.

Both fixed and sunk costs to produce information-commodities are considerable. The rise of the new information and communication technology makes the reproduction as well as the distribution of information-commodities cheap. Cheap reproduction of information-commodities by a producer goes hand in hand with cheap copying of information-commodities by other producers. It is therefore not unreasonable to expect that the cheap reproduction of information-commodities scares off potential producers, which causes too few information-commodities to be produced. 
Assigning property rights protects producers of information-commodities against reproduction and might thereby create a stimulus to the production of information-commodities. ${ }^{24}$ This can be achieved by means of patents, copy rights and trademarks. Certainly in the era of the internet, these kinds of protection are not watertight. It is often possible to copy information-commodities illegally, even when it is subject to a copy right. As long as information-commodities are produced, it is perhaps an unfair practice to produce illegal copies, but also a welfare enhancing one. When illegal copying becomes too excessive, then it may cause a restraint on the development of new information-commodities, or even bring the development of new information-commodities to a standstill.

Nevertheless, it seems quite improbable that the development of new information-commodities comes to a stop because of too unbridled copying. The scale at which illegal copies can be made is subject to limits. Copying often leads to some loss in quality, even when it concerns informationcommodities. Illegal versions of software for example are often obsolete and, moreover, are not accompanied by technical support. Illegal versions of books, movies and compact disks often don't quite have what the original has got, such as a nice accompanying booklet and a perfect performance. These differences will be reduced quickly by new technological developments. On the other hand, there will be new possibilities for the industry to introduce new differences, thereby enforcing its position. For that matter, there are also indications that illegal copies have positive effects for producers, because it is helpful in getting a larger market share. ${ }^{25}$ This implies that producers of information-commodities are wise not to be too restrictive in the protection of their intellectual property rights.

A strategy that is indeed frequently used, is even to give away information for free. Consumers, for instance, often have access to free web-pages, full of precious commodity-information. As explained before, this strategy can aim at the gain of market power in the future. Another reason to achieve a large market share can be found in advertising goals. More and more suppliers of webpages earn their money by means of advertising. Yet another reason is that supplier of informationcommodities often receive a fee of a telephone company on the basis of the traffic that they generate. Both for advertising goals and telephone traffic, it holds that more users imply more revenues. This is not without risk for social welfare. Indeed, incentives are no longer determined by the quality of the web-page, but by the number of people that make use of it. This implies that it pays off more to create a web-page that is somewhat appealing to many people, than one that is thrilling for only a small group, whereas the latter is socially optimal. ${ }^{26}$

We also want to give serious comments on the argument that the lack of intellectual property rights causes dynamic inefficiency in the form of too little innovation. When innovation is both sequentially and complementary, there exists both theoretical and empirical evidence that intellectual property rights cause both less innovation and less welfare. ${ }^{27}$ Sequential innovation is innovation where each invention elaborates on another. Complementary innovation is innovation that causes some central higher goal to be reached with higher probability. The problem of too strong intellectual property rights in this context is that it prevents competitors from making use of existing inventions to generate further innovation. Both sequential and complementary innovation seem to be pervasive in the new economy. 


\subsection{Price Discrimination}

Whereas naive contemplation on the new economy quickly leads to the idea that the ideal of the perfectly competitive market will finally be reached, we have already indicated that the new economy offers at the same time ample opportunities to build up and maintain monopoly positions. Subsequently, a producer who has achieved a monopoly position will take, is likely to exploit it to the full. To this end he may choose from a rich spectrum of opportunities that consist of various forms of price discrimination. The internet offers great opportunities to apply price discrimination, precisely because it is in principle open to producers to charge each buyer a different price.

Price discrimination of the first degree coincides with a complete appropriation of the consumer surplus by the producer. In order to be able to apply price discrimination of the first degree, the producer needs to know the reservation prices of all consumers, after which he will charge it as the price. The sum of consumer and producer surplus is maximal when price discrimination of the first degree is applied, and it equals the sum of consumer and producer surplus under conditions of perfect competition. There is, however, a reallocation of surplus from consumer to producer, which might be thought of as undesirable. Price discrimination of the first degree is in any case a theoretical extreme, which will never be achieved in practice.

Nonetheless, the internet makes it possible for producers to approach this extreme more closely. Not only because of the possibility to deal with each consumers individually, but also because of the possibility to collect large amounts of information about him or her. Purchasing behavior in the past, search-terms fed to search-engines, as well as the search behavior inside web-pages offer information about the characteristics of the consumer, and provide an indication of his or her reservation price. The internet also displays a high degree of interactivity. Search behavior that reveals certain characteristics of the consumer, can immediately be matched by an electronic offer.

In the case of price discrimination of the second degree, all consumer are offered the same spectrum of choices. But because of different preferences, consumers will make different choices. A frequently occurring case of price discrimination of the second degree is to offer discounts when a certain amount of the product is purchased. A frequently occurring practice for informationcommodities is to offer the same information-commodity in a number of versions that each are priced differently. This practice is sometimes called versioning.

We expect that price discrimination of the second degree will boom in the new economy. This will occur in the traditional way, in the form of discounts when large amounts of a commodity are purchased. This will also take a somewhat more subtle form when a package of informationcommodities is offered, a package consisting of the combination of a number of single informationcommodities. Since the marginal costs of offering additional information-commodities are nil, this constitutes a fairly cheap strategy for firms, which on top of it may also ensure that a large market share is attained quickly. As we have argued several times already, a large market share is of crucial importance in the sale of information-commodities. As far as the sales of packages of information-commodities leads to wider distribution of them against lower costs, this practice is attractive from a welfare point of view. 
Versioning is a form of price discrimination of the second degree which is very attractive for the producers of information-commodities, but less so from a social point of view. For many information-commodities it holds that a firm produces first a superior, all-embracing version. Thereafter, it is fairly cheap to produce a second type of information-commodity by elaborating it and creating simpler variations. Concrete examples are information services that offer for instance financial information, where the price charges for real-time information is a multiple of delayed information. Or the (un)availability of all kinds of gadgets for a software package, the comprehensiveness of a database, or the number of search options on a browser.

In case all consumers prefer the superior information-commodity, it is clear that it is not socially desirable when producers offer several versions of the same information-commodity. It is then not only the case that some consumers get an inferior product, but on top of this producers have to make more costs to produce this inferior product. In addition, there are incentives for producers to limit the quality of the inferior commodity, because otherwise consumers won't buy the superior product with the higher profit margin. ${ }^{28}$

Versioning will also be used as a marketing tool. Low costs of reproduction of informationcommodities, combined with versioning, make it possible to take care of problems caused by the fact that information-commodities are experience goods. Producers may offer inferior versions of their information-commodity for free as a sample copy to give consumers more insights into its value. As far as this suppresses the outlays on advertising, it is a positive effect of versioning.

\subsection{Competition Policy}

Monopoly positions are a reason for concern to competition authorities. As far as the sector for information-commodities is concerned, the negative effects of monopoly positions in the short run may be limited if the dynamics that are potentially available in the information-commodities market, are not taken away by a too generous protection of intellectual property rights. The fabulous dynamics that are at current present in the information and communication technology sector, cause many monopoly positions to be only temporary ones.

Moreover, even after a monopoly position has been achieved, the opportunities for a monopolist to exploit its market position are often limited. To keep potential entrants out, it is necessary to use limit pricing. The monopolist needs to set its price low enough to deter potential entrants. To apply these arguments, however, it is of crucial importance that the opportunities to entry are guaranteed.

There is yet another important characteristic of information-commodities, that has a competition improving effect. This is the fact that information-commodities are durable goods. Informationcommodities are in principle not subject to wear. They therefore display similarities to the ever burning light bulb. Producers of durable goods will have to decrease their prices over time to expand their market share. Consumers anticipate on this and will postpone their purchase as much as possible. This makes it difficult for producers to appropriate the entire consumer surplus, even if they occupy monopolistic positions. In other words, an always existing potential entrant in the market for information-commodities is the already present supplier itself. ${ }^{29}$ The durable character of information-commodities implies that even a monopolistic supplier of an information- 
commodity has an incentive to innovate. The only possibility to remain profitable is by introducing improved, or even completely new, versions.

\section{Information-infrastructure}

After the treatment of commodity-information and information-commodities, it is time to pay attention to a third important aspect of the new economy: information-infrastructure. The information-infrastructure consists of everything that makes it possible to store, search, copy, filter, manipulate, see, send and receive information. We have already argued that the informationinfrastructure reinforces the importance of certain less traditional properties of information, and thereby creates part of the specific possibilities and problems of the new economy. The information-infrastructure itself, however, also introduces a number of interesting economic aspects.

Where we expect commodity-information to cause mainly transparency increasing and transaction costs decreasing effects and thereby ample opportunities for a sunny future, yet we foresee scattered showers for information-commodities as a consequence of the dangers of monopolistic market structures, the information-infrastructure is likely to give occasion for stormy weather. The specific characteristics of the information-infrastructure can easily give rise to a problematic market structure. In this section we look closer into two of these characteristics, network externalities and the need for standards.

\section{$5.1 \quad$ Networks}

The information-infrastructure of information-commodities (as well as the informationcommodities themselves in many cases) gives rise to positive network externalities. ${ }^{30}$ Network externalities are not a novelty of the new economy. They are also present in traditional sectors of the economy, for instance in telephone networks, railway networks and pipelines for oil or gas. What might be different in the new economy is the abundance of network externalities, both in the form of physical and virtual networks.

The original idea behind network externalities is simple. In a network with $n$ users, there are $n-1$ possible links for each user. The total number of links in a network with n-1 users is then equal to $\mathrm{n}^{2}-\mathrm{n}$, a quantity that increases quadratically in the number of users. In that case, the value of a network increases quadratically in the number of users as well. This principle, known as Metcalfe's law, relies on the rather simplistic assumption that each link in a network has equal value as a starting point. A somewhat more economic approach tells us that the first links in a network have the highest marginal revenue, whereas later users show by self selection to be of lesser value. Nevertheless, it remains true that large connected networks are preferred by everyone over many isolated smaller ones.

There exist network externalities when the value of a product for one user depends on the number of other users. Examples are telephone, e-mail, internet, fax and modems. These products share the characteristic that it takes them often a long time to boom after they have been introduced. All of a sudden, just after crossing a threshold, there is often an explosive growth, such happened, for instance, in the development of mobile phones. 
In an industry with positive network effects it is often of great importance to have the largest market share. Positive network effects are self-enforcing as the network grows, which makes growing ever more easy. All reasons mentioned so far for building up a large market share quickly are confirmed by the large number, at the moment still loss-making, internet firms, which follow the strategy of building up a large market share as fast as possible in the form of a large customer base. Services, like access to the internet, or the availability of a personal internet page, are usually offered for free, with fast growth as a goal. Revenues are only expected in the future.

Positive network externalities are accelerated because consumers have incentives to be eventually part of the largest network. It is therefore of the greatest importance to producers to convince consumers, which have to make costs and therefore have to make a choice, that their network will be the largest one and that its technology will become the standard. The announcement of a new product may therefore be equally important to the actual introduction of it, because it may make consumers decide not to pass over to the purchase of a competitive product.

The problem of lock-in that was mentioned for the case of information-commodities, returns with great intensity for the case of information-infrastructure. As soon as a consumer has chosen to use a certain technological standard, it will often be very difficult for him or her to pass on to another technology, because of switching costs. Switching from one generation of computers to the next one causes for instance software problems and a need for renewed training of employees. On top of this, there are often investments in several, complementary and durable capital goods in the case of information-infrastructure, which are specifically appropriate to a certain kind of information technology, which reinforces the lock-in.

An additional problem for the case of networks is that there is not only individual lock-in, but also collective lock-in. It is not sufficient for a consumer to overcome his own switching costs. Consumers have to be convinced that others will do the same. This implies that the disciplining force of potential entrants deteriorates. It is no longer sufficient for entry to persuade customers on an individual basis. Consumers should be convinced that other consumers will pass on to a new technology as well. A potential entrant has to be very strong to effectively consider entry. This observation also offers a rational explanation of the sky-high stock price of many firms that are active in the new economy. ${ }^{31}$

Another consequence of network externalities is that existing technologies, as a consequence of individual and collective lock-ins, are used far past their socially optimal date. The general tradeoff for producers is either to develop a completely new technology, or a technology that is compatible with the existing technology. The former is only possible if it concerns a revolutionary improvement over existing technology, which is hardly ever the case. The latter caused the introduction of new, complementary, and durable capital goods, which might lead to further delay in technological innovation.

There often are many interdependencies between information-commodities and informationinfrastructure. This is particularly so because of the many systems that are part of the latter. To introduce new technologies, it is often necessary for firms to focus their attention not only on their competitors, but also on firms with whom they may collaborate. A prominent example of 
successful collaboration is the one between Microsoft and Intel. From a competition policy point of view, however, this causes the formation of huge centers of power, with a considerable twilight zone between collaboration and abuse of power.

The risk of monopolization is, therefore, tremendous in the presence of positive network externalities. An exception to this might be the case where consumers have such a large desire for variety that several networks may co-exist.

It is well possible that the above mentioned problems are less severe at the moment than in the somewhat distant future. The fabulous dynamics of the information and communication technology sector makes monopoly positions to be temporary. As soon as the speed of technological innovation diminishes, however, it is nearly impossible to enter into a sector with strong network externalities and one monopolist. Powerful policy by competition authorities may then prove to be crucial to avoid abuse of monopolistic positions.

\subsection{Standards}

It is in principle possible to distinguish open and closed standards, where the former concern technology that is accessible for all producers, and the latter technology that is protected by means of intellectual property rights. A closed technology is seemingly more attractive to a producer. The advantage of an open technology for a producer, however, is that an open technology makes it far easier to build up a large market share fast, and to profit from the advantages that go with that. Moreover, very often producers will have to collaborate, offering complementary products to one another, which is easier in the case of an open technology. The relationship between Microsoft's operating system and application software shows that also an intermediate form may be stable.

An important way to fight the formation of monopolies, is by realizing open standards. As soon as a certain technology has the largest network by far, it is possible to promote competition by making this technology an open standard. Standards make switching costs decrease considerably and take care of the formation of one large network, not unimportant in the case of positive network externalities. An open standard shifts competition between networks to competition on a network. Standards can differ immensely with respect to the amount of detail. The more detailed the standard, the less possibilities producers have to differentiate their products.

The government may play a role in the creation of standards by setting up independent institutes that determine them. In some cases such an independent institute should have the possibility to impose compensation payments. Huge conflicts about standards might arise when several companies have an interest to make their own technology the standard. A role might be played here by auction mechanisms that should be designed in such a way that the most efficient standard will be realized. The recent auctions in Europe for UMTS-licenses show that the auction design is, though far from trivial, of crucial importance. A matter of concern will be to maintain the independence of such an institute, and to keep welfare its objective.

Standards do not necessarily have to be taken care of by government related institutions. They may also be managed privately. A private enterprise that controls a standard should then be obliged to 
give other parties access to the standard at fair tariffs. An advantage of privately managed standards is that a private party has stronger incentives to improve and to warrant the integrity of the standard.

We have already observed that as long as it is unclear to consumers whether a certain technology will make it, they will be very reluctant in purchasing its compatible products. It is important for producers to convince consumers that their technology will break through. A standard might be helpful to overcome such problems. This provides additional reasons why a standard is not only in the interest of consumers, but often also in the interest of producers. Government intervention is therefore not always necessary to get to a universal standard. It is not unconceivable that the market itself creates institutions that determine standards, for instance in the form of strategic alliances between producers. From a competition policy point of view, such a development is not without danger. An alliance might effectively put competition out of business, if it possesses the intellectual property rights and the standard is only open within the alliance.

As soon as a monopoly has emerged, the government has a number of options. The European legislation offers more possibilities here than the American. The government may abstain from intervention, thereby using the argument that it is efficient to have one supplier only in a natural monopoly. This may also be an interesting option when there is a sufficient amount of potential entry. The government may also improve the conditions under which more entry is possible, for instance by introducing an open standard and the pursuit of a restrictive policy when it concerns the protection of intellectual property rights. The current legislation for the protection of intellectual property rights seems far too rigid in this respect. The option of flexibility when it concerns length and scope of intellectual property rights may be most useful to permanently maintain the appropriate balance between sufficient competition and sufficient incentives to innovate

In the short run, property rights will be less important anyhow, because of the fast pace of technological progress that makes the vast majority of monopoly positions temporary. In the mid term, under the scenario where technological progress has come to an end, and a large number of markets with strong network externalities and huge switching costs threaten to come about, strong intellectual property rights are undesirable.

The government might break up a monopoly, as decreed in the Microsoft case. This is particularly attractive if it is possible to organize competition on a network. In other cases, the government may regulate the monopoly, for instance by installing an independent regulator. An interesting discussion that will most likely emerge here concerns the scope of the industry to be regulated, because there is simultaneously convergence between and globalization of industries. ${ }^{32}$

Sectors which traditionally have been separated from each other, such as the telecommunication, media, and information technology sectors, all produce information-commodities and make use of a common information-infrastructure. ${ }^{33}$ Some of these sectors are not regulated at all, for instance the information technology sector. Others, like the telecommunication sector, have to deal with supervisors. Frontiers, traditionally of great influence on trade flows, are hardly of any influence for a medium like the internet. It is therefore highly debatable whether a local regulation of the internet is meaningful. All this seems to pledge for one global regulator for the information and communication technology sector. There are, however, also advantages to have several regulators. 
The case of several regulators makes yardstick competition possible; industry specific regulators have more specific technological knowledge available and it is often easier to give the right incentives to regulators when they confine themselves to a single industry.

\section{Conclusions}

There seem to be sufficiently many similarities between the conditions under which the existing micro-economic theory provides its often useful insights, and the fundamental properties of the reality of the new economy. As a consequence, there is no need for a 'new economy' in a theoretical sense. This has the advantage that important aspects of the new economy can be understood by means of existing economic insights.

We distinguish information in commodity-information on the one hand, and informationcommodities on the other hand. Commodity-information refers to information about commodities, which is available in the new economy against lower costs and in greater supply. This is information that is used to make better decisions. Information-commodities are all commodities that can be represented digitally. Information-commodities are used directly in consumption and production processes. To achieve an optimal processing of commodity-information and information-commodities, a sizeable information-infrastructure is needed in the new economy.

There is reason for a moderated optimism towards the opportunities offered by the new economy in the area of commodity-information. A more extensive and cheaper exchange of commodityinformation causes better individual decisions as well as more transparent and more competitive markets. It is important, however, not to lose sight of the problems for the nature of competitive processes caused by the new economy. Collecting information is costly, which leads to the threat of an inefficient amount of absorption. Information intermediaries will try to find their niches in the section of information. Firms and credit card companies may profit from the problems of reliability of information and physical deliveries, and even increase these problems on purpose. There is the possibility that firms try to oppose to the potential threat of a greater transparency by applying or strengthening product and price discrimination. Finally, one may expect new problems in the transport of commodities that are traded via the internet.

There seems to be reason for some alertness where it concerns the developments in the new economy in the domain of information-commodities. Their properties, in particular the presence of large fixed production and distribution costs, and very low marginal costs, may give rise to the emergence of dominant suppliers. Suppliers also have various means to promote such a market structure, for instance far reaching forms of product differentiation, lock-in of consumers, and the gathering of intellectual property rights. Although increased opportunities to learn about the preferences of consumers and to play along with them may cause great welfare improvements, those same opportunities lead to an appropriation of a substantial share of the consumer surplus.

Monopolistic market structures seem to be unavoidable where it concerns the informationinfrastructure. This is caused by the strongly present network externalities, both on the individual and on the collective level. It is also possible that firms further exploit a dominant position by striving for closed standards, that deter new entry effectively by means of the acquired property rights. The Microsoft case is only the first spectacular instance where the abuse of monopoly power 
in the information-infrastructure has caused the government to intervene. There are already several firms with similar positions, and other firms try hard to get to new ones.

In general, governments need to watch the new developments closely in order to pre-empt the problems mentioned. The current boom of companies that want to invest in the internet indicates that one may expect niches with a certain amount of protection. One of the courses of action the government could take, is to throw open and keep open the opportunities to entry of firms and institutions. The government can do so by means of direct competition policy, and intervention when companies play too big a role in setting up entry barriers. A good example of an intervention that was too late concerns the practice of claiming internet addresses, that are subsequently offered for sale against high prices. This is a typical form of inefficient speculation. In particular the market for information-infrastructure needs to be watched closely by competition authorities. It has a strong inclination to create market structures that are socially particularly undesirable, both from a static point of view, since they restrict the distribution of commodity-information and informationcommodities, and from a dynamic point of view, since they hinder the development of new technological standards. Both kinds of restrictions are undesirable from the perspective of the agent which controls access to, and transport on the internet.

Even more important perhaps is the role the government may play as provider of standards and transparency, including codes for the comparison of prices of products, which should be inclusive all kinds of markups for transport and insurance. Though the demand for such services may also provoke privately based responses - like a virtual consumers' association or a search engine like 'Are-you-sure?' - the role of the intermediary remains a competition disturbing one. The neutrality of the government in these matters simplifies the creation of reliability and promotes the transparency in markets. Full exploitation of the potential world-wide-welfare that is offered by the world-wide-web calls for a solid, government controlled, monitoring of the openness of the competitive process. 


\section{Literature}

Akerlof, G. (1970) The Market for Lemons: Quality Uncertainty and the Market Mechanism. Quarterly Journal of Economics (89), 488-500.

Arrow, K.J. (1953) Le Role des Valeurs Boursières pour la Répartition la Meilleure des Risques Econométrie. Colloques Internationaux du Centre National de la Recherche Scientifique (40), 4147.

Arrow, K.J. (1962) Economic Welfare and the Allocation of Resources for Invention. In: The Rate and Direction of Inventive Activity: Economic and Social Factors National Bureau of Economic Research, Princeton University Press, 609-626.

Arrow, K.J. (1978) Risk Allocation and Information: Some Recent Theoretical Developments. The Geneva Papers on Risk and Insurance (8), 5-19.

Aumann, R.J. (1976) Agreeing to Disagree. Annals of Statistics (4), 1236-1239.

Baye, M.R. \& Morgan, J. (2000) Information Gatekeepers on the Internet and the Competitiveness of Homogeneous Product Markets. Forthcoming in American Economic Review.

Belleflamme, P. (1998) Adoption of Network Technologies in Oligopolies. International Journal of Industrial Organization (16), 415-444.

Bessen, J. \& Maskin, E. (2000) Sequential Innovation, Patents, and Imitation. MIT Working Paper 00-01.

Binmore, K. (1994), Game Theory and the Social Contract, Vol. I. Cambridge, MA: MIT Press.

- (1998), Game Theory and the Social Contract, Vol. I. Cambridge, MA: MIT Press.

Blackwell, D. (1953) Equivalent Comparison of Experiments. Annals of Mathematics and Statistics (24), 265-272.

Blackwell, F. \& Dubins, L. (1962) Merging of Opinions with Increasing Information. Annals of Mathematical Statistics (38), 882-886.

Coase, R. (1972) Durability and Monopoly. Journal of Law and Economics (15), 143-149.

Debreu, G. (1959) Theory of Value. New Haven: Yale University Press.

DeLong, J.B. \& Froomkin, A.M. (2000) Speculative Microeconomics for Tomorrow's Economy. First Monday (5), 2.

Dixit, A.K. \& Stiglitz, J.E. (1977) Monopolistic Competition and Optimum Product Diversity. American Economic Review (67), 297-308. 
Dolfsma, W. (1998) Internet: an Economist's Utopia? Review of International Political Economy (5), 712-720.

Dolfsma, W. (2000) How Will the Music Industry Weather the Globalization Storm? First Monday (5), 5 .

Economides, N. (1996) Network Externalities, Complementarities, and Invitations to Enter. European Journal of Political Economy (12), 211-233.

The Economist, August 5th-August 11th Internet payments, the personal touch, p. 72.

Fontenay, E. de (1999) Should the Internet Care about Regulation: Regulation and Convergence. Netnomics (1), 173-185.

Hens, T. (1997) Stability of Tâtonnement Processes of Short Period Equilibria with Rational Expectations. Journal of Mathematical Economics (28), 41-67.

Herings, P.J.J. (1999) A Note on 'Tâtonnement Processes of Short Period Equilibria with Rational Expectations.' Journal of Mathematical Economics (32), 333-338.

Hirshleifer, J. (1971) The Private and Social Value of Information and the Reward to Inventive Activity. American Economic Review (61), 561-574.

Hirshleifer, J. \& Riley, J.G. (1995) The Analytics of Uncertainty and Information. Cambridge: Cambridge University Press.

Jones, R.A. \& Ostroy, J.M. (1984) Flexibility and Uncertainty. Review of Economic Studies (51), 1, 13-32.

Katz, M. \& Shapiro, K. (1994) System Competition and Network Effects. Journal of Economic Perspectives (8), 93-115.

Klemperer, P.D. (2000) Why Every Economist Should Learn Some Auction Theory. Working Paper Presented at the World Congress of the Econometric Society in Seattle.

Knight, F. (1921) Risk, Uncertainty, and Profit. Cambridge: The Riverside Press.

Laffont, J.J. \& Tirole, J. (2000) Competition in Telecommunications. Cambridge: MIT Press.

Menkhoff, R. (1999) Java and Object Standardization in the Internet - A Way to More Competition in the Software Industry? Netnomics (1), 107-126.

Milgrom, P.R. (1979) A Convergence Theorem for Competitive Bidding with Differential Information. Econometrica (47), 679-688. 
Milgrom, P.R. (1981) Rational Expectations, Information Acquisition, and Competitive Bidding with Differential Information. Econometrica (49), 921-943.

Milgrom, P. \& Roberts, J. (1986) Price and Advertising as Signals of Product Quality. Journal of Political Economy (94), 796-821.

Muth, J.F. (1961) Rational Expectations and the Theory of Price Movements. Econometrica (29), 315-353.

Nelson, P. (1974) Advertising as Information. Journal of Political Economy (82), 729-754.

Radner, R. (1968) Competitive Equilibrium under Uncertainty. Econometrica (36), 31-58.

Radner, R. (1979) Rational Expectations Equilibrium: Generic Existence and the Information Revealed by Prices. Econometrica (47), 655-678.

Scherer, F.M. \& Ross, D. (1990) Industrial Market Structure and Economic Performance. Boston: Houghton Mifflin.

Schinkel, M.P., On the Desirability of Public Disclosure of Medical Predisposition Test Results, Research Memorandum (30), Maastricht University.

Schinkel, M.P., Tuinstra, J. \& Vermeulen, D. (2000) Bayesian Learning in Mis-specified Models. Research Memorandum (8), Maastricht University.

Schmalensee, R. (1986) Advertizing and Market Structure. In: Stiglitz, J \& G.F. Mathewson (Red.), New Developments in the Analysis of Market Structure. London: MacMillan.

Shapiro, C. \& Varian, H.R. (1999) Information Rules: A Strategic Guide to the Network Economy. Boston, MA: Harvard Business School Press.

Stigler, G.J. \& Becker, G.S. (1977) De Gustibus Non Est Disputandum. American Economic Review (67), 76-90.

Vulkan, N. (1999) Economic Implications of Agent Technology and E-Commerce. Economic Journal (109), 67-90.

Whinston, A.B., Stahl, D.O. \& Choi, S.Y. (1997) The Economics of Electronic Commerce. Indianopolis: MacMillan.

Wilson, R. (1977) A Bidding Model of Perfect Competition. Review of Economic Studies (44), 511518. 


\section{Notes}

${ }^{1}$ See Hirshleifer \& Riley (1995)

${ }^{2}$ This coincides with the characterization of commodities by Debreu (1959).

${ }^{3}$ See Chapter 7 of Knight (1921) for an interesting discussion of the relationship between risk and uncertainty.

${ }^{4}$ See Blackwell \& Dubins (1962).

${ }^{5}$ Although this is an open philosophical puzzle of some interest.

${ }^{6}$ This is only true if the information does not lead to a reduction in the number of available choices, which can certainly be the case, for example in the purchase of insurance - the so-called Hirshleifer-effect, see Hirshleifer (1971). It is also well-known that when strategic effects are present, less information can lead to more favorable outcomes. On this point, see also Schinkel (1999).

${ }^{7}$ Bayesian learning is, as described in the following, widely seen as rational learning. Of importance for the effects of it is the structural specification of the relations that are to be learned. See on this subject Schinkel, Tuinstra \& Vermeulen (2000).

${ }^{8}$ See Radner (1979).

${ }^{9}$ See Arrow (1953).

${ }^{10}$ An analysis of the conditions under which convergence of a number of price adjustment processes takes place on a perfectly competitive equilibrium can be found in Hens (1997) and Herings (1999).

${ }^{11}$ Wilson (1977) and Milgrom (1979) analyse the decreasing auction and Milgrom (1981) the increasing auction.

${ }^{12}$ It can also be the case that groups with conflicting objectives collect too little information, and even ignore free information in order to avoid real conflicts, see Hirshleifer \& Riley (1995) and Jones \& Ostroy (1984).

${ }^{13}$ This is the so-called Hirshleifer-effect.

${ }_{15}^{14}$ See The Economist, August 5th-August 11th 2000, page 72.

${ }^{15}$ See Binmore (1994).

${ }^{16}$ The developments in virtual banking are of important concern for monetary policy. An increase of it is comparable to the creation of money, taking place outside the realm of central banks.

${ }^{17}$ In particular Microsoft has developed a protocol for this.

${ }^{18}$ See Baye \& Morgan (2000) for a formal model of this phenomenon.

${ }^{19}$ See Vulkan (1999) and DeLong \& Froomkin (2000).

${ }^{20}$ For further critiques to the idea that the internet leads to markets with perfect competition, see Dolfsma (1998).

${ }^{21}$ For further insights into optimal investment in research and development, we refer to Scherer \& Ross (1990), in particular Chapter 17.

${ }_{22}^{23}$ Akerlof (1970) was the first to point out this kind of problems in his path-breaking work.

${ }^{23}$ See Nelson (1974) and Milgrom \& Roberts (1986). For an exposition on excess advertisement in Nash equilibrium, see Schmalensee (1986).

${ }^{24}$ The United States Congress it obliged by the constitution to promote the progress of science and useful arts by granting exclusive rights to authors and inventors for their writings and inventions during a limited time span.

${ }_{25}$ A good example is the recent commotion around Napster, against which prominent artists like the rock band Metallica protested. We refer to Shapiro \& Varian (1999) for a defense of the stance that illegal copies can be beneficial for sales.

${ }^{26}$ For a similar example concerning television broadcasts, see DeLong \& Froomkin (2000).

${ }^{27}$ See Bessen \& Maskin (2000).

${ }^{28}$ A nice example of inefficient versioning are the popular cheap scanners used for mass consumption. In order not to fit into the patent description of a copying machine, and thereby avoid the almost price doubling rights, are made unnecessarily slow.

${ }^{29}$ The phenomenon that a monopolist of a durable commodity competes with itself was noticed by Coase (1972).

${ }^{30}$ See Katz \& Shapiro (1994) for an overview of the area of network externalities.

${ }^{31}$ This also makes us understand that Microsoft stocks has to suffer so much from the proceedings instituted against it by the US government, with as goal to make Microsoft's dominant position in the market for operating systems to be subject to greater threats in the future.

${ }^{32}$ See Chapter 7 of Laffont \& Tirole (2000).

${ }^{33}$ For the specific problems that the convergence of industries poses for regulation, see de Fontenay (1999). 